\title{
Educación a distancia: apuntes sobre sus orígenes y justiprecio como recurso práctico y poderoso para la educación permanente a la luz del cambio intrageneracional
}

\section{Ed. Silvia Ruiz Badilla}

La educación es un proceso continuo y permanente que tiene por objeto acercar gradualmente al ser humano a la perfección al mismo tiempo que le permite proyectarse en los planos individual y social, con el último propósito de que su realización y perfección contribuyan al progreso de las personas que lo rodean, de su comunidad y de la sociedad en general.

La educación, en palabras de Pérez (s.a.), " no prepara al hombre sólo para sobrevivir, sino para vivir, desarrolla su conciencia, sus sentimientos e induce (...) al ser humano a la reflexión sobre sí mismo. Prepara no sólo para ganarse la vida, sino para ser una persona feliz, realizada, con sentido, de utilidad y en función no sólo de su persona sino de la sociedad." 
Las personas adquieren, a través de la educación valores, destrezas, hábitos, actitudes ante la vida y una serie de conocimientos que le permiten, en su conjunto, enfrentarse a las nuevas situaciones que la vida de manera exitosa y sin perjudicar la dignidad de los otros seres humanos.

Pero ¿es educable el ser humano en realidad? Todo ser humano posee una cualidad esencial y exclusivamente humana que le permite ser educado. Esa cualidad es la educabilidad, que hace al hombre susceptible de modificación y perfección. El ser humano es educable porque tiene la capacidad de reflexionar, de realizarse, de cambiar el rumbo de su vida y de adaptarse según sus necesidades e intereses.

De acuerdo con lo anterior, queda claro que la educación, en cualquiera de los matices o formas que se presente, constituye el curso de solución más efectivo para alcanzar el desarrollo pleno de las potencialidades de cada ser humano y, por lo tanto, de cada nación. Existen básicamente dos modalidades educativas que nos permiten llegar a tales niveles: la modalidad presencial y la modalidad a distancia; entendida cada una como complemento de la otra, en la difícil e inconclusa tarea de permitir una educación accesible, continua y de calidad a todas las personas del mundo, sin importar su raza, religión, origen o condición social.

Es precisamente, por la complementariedad a la que aludíamos en el párrafo anterior, que, en este ensayo, hemos decidido ocuparnos de la educación a distancia (EAD) y de su papel en la construcción de la sociedad y en la plena realización personal, no bajo la idea de que existen dos tipos de educaciones según la forma y los contextos en que se presenten (a distancia y presencial), sino considerando a la educación como una sola e indivisible, con configuraciones distintas.

La modalidad presencial, conocida también como educación formal, se caracteriza, principalmente, por requerir 
la asistencia del docente y de los discentes en un espacio y en un momento determinado, ya que el conocimiento se trasmite personal y unidireccionalmente (del docente hacia los estudiantes), con distintas metodologías y recursos didácticos. El aprendizaje del estudiante, en esta modalidad, no es autónomo ni tampoco puede llevarse a cabo a su propio ritmo, sino que depende de las directrices y los objetivos propuestos por el profesor. En algunos casos, los medios tecnológicos soportan el proceso de enseñanza, pero no constituyen elementos indispensables.

En el caso de la modalidad a distancia, que también se conoce como educación abierta, no presencial o a distancia, la interrelación entre el docente y los estudiantes se da en diferentes tiempos y espacios a través de medios de comunicación impresos, audiovisuales, electrónicos o multimedia; con mínimos o ausentes encuentros presenciales o virtuales. En esta modalidad, la comunicación entre el estudiante y el docente o los otros estudiantes es constante y bidireccional, y el profesor desempeña el papel de asesor que de trasmisor de conocimientos.

Pese a todas las ventajas y naturaleza de la modalidad presencial, es innegable que la educación a distancia es una ruta más abierta por la que miles de personas alrededor de todo el mundo seguirán transitando, con el propósito de educarse y capacitarse en el desempeño de múltiples competencias, mismas que se requieren para cumplir un rol más activo y exitoso en la construcción de la sociedad y de la plena realización personal en cualquier lugar y momento de la vida, pero de manera especial cuando, por razones de distancia y disponibilidad horaria, a una persona le resulte prácticamente imposible recurrir a la otra modalidad de estudio presencial convencional.

La génesis primaria de la educación a distancia se remonta a los comienzos de la existencia del ser humano y de 
su necesidad de comunicarse, la cual pasó de gestos, sonidos, signos, símbolos gráficos, jeroglíficos, etc. hasta llegar al lenguaje y a la escritura, los cuales constituyen las formas de comunicación más usados en la educación presencial y a distancia, respectivamente.

García (1999) coincide con lo anterior, pero hace énfasis en la invención de la imprenta, los efectos de la educación por correspondencia y la invención y consecuente uso de los medios de comunicación. No obstante, señala cinco como las principales causas del establecimiento, éxito y desarrollo de la EAD tal y como la conocemos hoy: los avances sociopolíticos, la necesidad de aprender a lo largo de la vida, la carestía de los sistemas convencionales, los avances de las ciencias de la educación y las transformaciones tecnológicas.

Sobre los avances sociopolíticos, García (1999) afirma que el término de la guerra y el aumento de los índices demográficos provocaron una gran demanda social hacia una educación escolarizada y un sistema educativo democratizado. Tal situación requería de profesionales capacitados para que se desempeñaran en las nuevas necesidades que imponía la sociedad industrializada. Sumado a esto, abundaban las personas pertenecientes a los sectores sociales más desfavorecidos (residentes de zonas geográficas alejadas, amas de casa, emigrantes, reclusos, etc.) que, aunque contaban con motivación y suficientes posibilidades para ser exitosos académicamente, no podían asistir a clases debido a su misma condición. El problema ordenaba disponer rápidamente de espacios para satisfacer todas estas demandas, aún cuando los sistemas educativos no contaran con los recursos ni la infraestructura suficiente.

Asimismo, el anhelo por una formación personal, cultural o profesional fortalecía la demanda por una oferta educativa, en especial una que brindara mejores oportunidades 
para la clase trabajadora que debía seguir trabajando para subsistir. Además, los cambios generacionales empezaban a marcarse con rapidez y se hacían cada vez más evidentes en la población. Las personas cualificadas carecían de las competencias necesarias para hacer frente a los nuevos requerimientos de su profesión.

Pero, pese a que el reclamo se hacía más fuerte, los recursos económicos, materiales y humanos en el campo educativo, seguían siendo escasos. El sistema convencional no daba a basto con las exigencias de los nuevos tiempos. Los gobiernos debían encontrar una forma nueva y rentable que acogiera a todas estas personas, sin menoscabar la calidad de la educación. La apertura de espacios educativos adecuados y la flexibilización de los cursos eran requisitos básicos para el nuevo sistema. La educación a distancia fue la respuesta acertada a las peticiones de la sociedad. Pero, como se trataba de un sistema novedoso, se tuvo que invertir en recursos humanos y materiales para alcanzar tan esperada transformación.

La proliferación de los aparatos tecnológicos y el avance en las ciencias de la educación jugaron un papel trascendental en la implementación del nuevo sistema y, de manera muy especial, en el aumento de la democratización de la educación. Con los medios de comunicación se acortaron las distancias y la comunicación se volvió más rápida y efectiva. Además, los avances de las ciencias de la educación hicieron posible que la enseñanza se llevara a cabo de una forma menos personalizada y sin la presencia del profesor. Estas condiciones prepararon el terreno para contar indefinidamente con un sistema que satisfacía, por un lado, las necesidades educativas impuestas por los vertiginosos cambios y, por otro aún más importante, el derecho de todas las personas a la educación.

Se contaba entonces con un sistema que permitía aprender y acreditar competencias de una manera más flexible 
y oportuna, sin límites de tiempo ni espacio, gracias al soporte tecnológico y a los avances en las ciencias de la educación.

Pero la tecnología, aunque con una presencia un poco heterogénea, ha figurado siempre en los distintos procesos evolutivos de la educación a distancia. García (1999), basado en Garrison (1985 y 1989) distingue tres períodos o "generaciones": correspondencia, telecomunicación y telemática, a las que más tarde se les suma la cuarta generación: la enseñanza vía Internet, conocida también la generación del campus virtual o enseñana virtual (García, 2003).

La primera generación de correspondencia fue la de mayor duración: abarcó desde finales del siglo XIX hasta principios del XX. En este período se usaron principalmente los textos rudimentarios escritos a mano; luego, apareció la imprenta y, con ella, una rápida producción de textos, los cuales se enviaban a los estudiantes a través de los servicios nacionales de correos. Aunque en esta etapa nacieron varias invenciones que revolucionaron las formas de comunicación entre la gente, como el teléfono, la radio y la televisión, no fueron aprovechados sino hasta la segunda generación..

En la fase de telecomunicación, que expandió desde 1970 hasta finales del siglo XX, apareció la figura del tutor y el teléfono se convirtió en un instrumento útil para la interacción entre él y sus estudiantes. Además, se utilzaron varios recursos audiovisuales, como audiocasetes, diapositivas y videocasetes. Pese a esto, el material escrito continuó prevaleciendo.

La tercera generación (telemática) estuvo básicamente presente a finales del siglo pasado y se distinguió por la combinación de los distintos medios educativos con las telecomunicaciones, por medio de la informática. Durante este período las computadoras personales adquirieron gran 
relevancia y se lograron romper definitivamente los límites de tiempo y espacio, que hasta ese momento habían prevalecido en la enseñanza.

La cuarta generación es precisamente la etapa en la que nos encontramos. Actualmente la EAD es parte de un sistema globalizado, al que la mayoría de personas tiene acceso a través de la World Wide Web (WWW) de la internet o Red Mundial y de las múltiples plataformas multimedias y softwares especiales que se han diseñado con fines pedagógicos. Este sistema permite la comunicación por audio, video, gráficos, texto, etc. de manera simultánea o asincrónica, con uno o múltiples individuos. Además, debido a los mismos mecanismos electrónicos que se utilizan se logra agilizar la realimentación, tan necesaria en cualquier proceso educativo. Para Castellanos (2004) la educación virtual es una modalidad más sofisticada de la educación a distancia; no obstante, Tintaya (s.a.) le otorga una connotación mayor cuando la reconoce como "la educación del siglo XXI", debido a los principios que la caracterizan: autoeducación, autoformación, desterritorialización, descentración, virtualización, tecnologización y sociabilidad virtual.

Es indudable que con los avances tecnológicos en el campo de la comunicación y la información se están generando mayores oportunidades de relación con los demás, aún para las personas de lugares remotos y pocos desarrollados. Los efectos de los cambios económicos, tecnológicos, científicos, etc. que se desarrollan en la aldea global se ven plasmados directamente en la educación, sea para su desarrollo o para la imposición de nuevos retos. En este mundo globalizado las tecnologías de la información ocupan un lugar preponderante en el desarrollo de los individuos y de las naciones, siendo este el motivo por el que se hace necesario que los países, desarrollados y en vías de desarrollo, inviertan considerablemente en tecnologías de información y en educación. 
Ninguna sociedad, sin importar su nivel de desarrollo, está exenta a cambios, y su evolución resulta casi imposible sin un sistema educativo viable (Castellanos, 2004), que le permita fundar las bases para enfrentarlos con propiedad y pertinencia.

Costa Rica se ha ido adaptando poco a poco a estas transformaciones. El éxito de la Universidad Estatal a Distancia así lo constata: su apertura estaba respaldada por varios argumentos, entre los que sobresalían el problema de financiamiento que sufría la educación superior y la necesidad de una mayor democratización, acentuada por una fuerte demanda en la matrícula. Aunque constituyó todo un campo pionero e innovador que implicó cambios de paradigma, fue creciendo y expandiéndose a lo largo y ancho del territorio nacional, permietiéndole el acceso a una educación de calidad a miles de costarricenses de zonas alejadas y con escasos recursos económicos. Hoy, 30 años después de su fundación, esta institución continúa proporcionando instrumentos adecuados para el perfeccionamiento y formación permanente de todos aquellos habitantes, que por una u otra razón, no pudieron o no quisieron, incorporarse al sistema formal universitario (Ley de creación de la Universidad Estatal a Distancia, Art. 26, 1977).

Son varios los puntos ventajosos de la educación a distancia, entre los que se destacan los relacionados con su potencialidad masificadora, la metodología de enseñanza empleada y la relación costo-eficacia.

La capacidad para acoger a un mayor número de estudiantes constituye una de sus causas de aparición más importantes. A esto, se le suma la oferta de un currículo extenso, cada vez más competitivo y que supera -en algunas oportunidades- los de algunas instituciones superiores de modalidad presencial. 
Con respecto a la metodología de enseñanza, se alaba el hecho de que las decisiones sobre cuándo y dónde aprender son tomadas por el propio estudiante, siendo éste el único responsable del ritmo de aprendizaje

En lo que se refiere al nexo entre costo y eficacia debemos, subrayar que la racionalización del proceso y la forma en que se distribuye el trabajo hacen que se reduzcan sus costos y se vuelva más rentable y eficaz. Tal resultado constituye un factor beneficioso para la población estudiantil, ya que representa una formación permanente a bajos costos y sin los obstáculos de la educación presencial, como el cumplir horarios o el estar presentes en recintos específicos para el desarrollo de la clase, que llevarían, en ciertos casos, al abandono de las responsabilidades adquiridas en el campo familiar y laboral.

Pese a todas estas ventajas, se han señalado también varios elementos negativos que habría que mejorar y superar. Carrión (2005) los agrupa en cuatro áreas, de las cuales destacaremos solamente las siguientes tres: el alumno, la metodología de las investigaciones realizadas y el papel de las TIC.

Sobre el alumno, el autor nos comenta que existe un gran número de estudiantes que abandonan la educación a distancia debido a una serie de factores externos e internos, como: las obligaciones laborales, la atención a la familia, la falta de motivación, la deficiencia en la formación básica y los malos hábitos y técnicas de estudio. Cuando los estudiantes desertan se afectan a sí mismos, por las frustraciones y sentimientos de fracaso personal que se generan en él, y dañan la reputación de la institución, ya que se comienza a cuestionar la eficacia cualitativa de la institución y a poner en peligro el presupuesto que se le otorga.

En cuanto a la metodología de las investigaciones realizadas sobre esta modalidad, Carrión (2005) señala que la 
mayoría de ellas parten con vicios y concluyen con una visión general positiva sin argumentos fuertes que demuestren su calidad. Aunado a esto, se cuestionan la validez y la fiabilidad de los instrumentos utilizados en los estudios y se destaca la preferencia de investigaciones dirigidas a aspectos individuales, como un curso o un tipo de tecnología, en lugar de realizar estudios globales donde interaccionan varios elementos.

El uso de las tecnologías de la información y de la comunicación (TIC) también es fuertemente criticado. Se argumenta que, a pesar de que han evolucionado y transformado enormemente a la sociedad, no se han utilizado para beneficiar la calidad educativa, pues no se les ha aprovechado suficientemente en los procesos de enseñanzaaprendizaje. En este sentido, se critica que es común encontrar reproducciones de textos en los diseños multimedia, pasando el contenido y la forma de un texto impreso a uno digital. Además, en muchas ocasiones, la información que se presenta aparece de manera desorganizada y confusa, con lo que el estudiante termina desorientándose y sin deseos de estudiar.

Como se aprecia, la EAD no sólo se ha destacado por sus ventajas, sino que presenta una serie de puntos críticos que se deben fortalecer. Aún así, su futuro es muy esperanzador, sobretodo cuando se piensa en las innumerables oportunidades que ofrecen las TIC a todas las personas alrededor del mundo y, particularmente, a las que viven en los países menos desarrollados, pues con ellas, podrán tener acceso a educación en cualquier momento y lugar en el que se encuentren.

Pero, la educación permanente como necesidad del ser humano no es un asunto restringido a nuestros días, ha existido desde el comienzo de la misma humanidad; sin embargo, como concepto es algo reciente y constante en el 
ámbito educativo debido a la praxis y a la reflexión de la educación actual, acentuada por los rápidos cambios en los distintos campos de la sociedad (Vásquez, 2005).

En este sentido, cuando aludimos a "educación permanente" nos estamos refiriendo a una praxis antigua que abarca todos los procesos educativos que se dan a través de la vida, desde que nacemos hasta que morimos. Como vemos, este concepto supera al de la educación tradicional, pues no se limita a un tiempo, a un espacio o a un sistema determinado, sino que se refiere a un proceso más libre y dinámico, dirigido a satisfacer las funciones vitales y sociales del ser humano y a quien se le considera como individuo incompleto y en un constante estado de transformación. Algunas veces, estos cambios son impulsados por factores externos, como en el caso de la revolución tecnológica; otras, nacen en cada persona en búsqueda de una realización personal. Por esto, cuando hablamos de educación no podemos dejar de pensar en el cambio y la evolución social.

En nuestros tiempos, las distintas generaciones son testigos fieles de las rápidas y constantes de las transformaciones en la política, economía, religión, ciencia, tecnología, etc., por citar algunos ejemplos; y es precisamente por esos cambios y la conciencia que la sociedad tiene de ellos, que surge la interrelación y sus subsecuentes efectos entre cambio y educación.

Fernández (2001) en su libro "Educar en tiempos inciertos" postula tres tipos de cambios: suprageneracional, intergeneracional e intrageneracional. El límite entre cada uno de ellos no es concreto ni específico, sino que pasan por largos períodos de transición y de indefinición.

El cambio suprageneracional es el que ocurre de una generación a otra pero de modo imperceptible para la mayoría de la población. En este proceso, la familia y la 
comunidad inmediata constituyen las instituciones encargadas de enseñar y los adultos se vuelven los agentes educativos para otros adultos menores, jóvenes y niños; es decir, el educador se establece como tal por medio de dos factores: la edad y la experiencia. Bajo esta permuta no existe un espacio destinado exclusivamente al aprendizaje y la función de la educación está centrada básicamente en la reproducción y no en la transformación.

El cambio intergeneracional, por su parte, sí es perceptible y claro entre una generación y otra o más de una generación. Puede, además, suceder en distintos momentos. Se trata del paso a un mundo generacional diferente del anterior y, como consecuencia, la generación anterior no puede guiar a la(s) nueva(s) generación(es) en su cambio. En este proceso hay una pérdida, la del mundo de las generaciones anteriores, que ven desaparecer lo conocido para adentrarse a algo nuevo y desconocido junto con los más jóvenes. En esta etapa las instituciones naturales (familia y comunidad inmediata) no pueden cumplir con sus funciones educativas, por lo que se necesitan nuevas instituciones y diferentes agentes que serán reconocidos por la sociedad, a saber: la escuela y el magisterio.

El último cambio que nos expone Fernández (2001) es el intrageneracional. Según el autor, esta mutación es perceptible y general dentro de una misma generación, debido a la veloz evolución de la misma sociedad; no sólo se entra a un mundo diferente del anterior sino que también se atraviesa por varios mundos distintos. Ejemplos de estos cambios son los que ocurren en las formas de organización de las sociedades, como el mercado de trabajo, la organización empresarial, las formas de comunicación, etc., que coaccionan a la población hacia una readaptación permanente en la manera de vivir, de trabajar y de socializar con los demás. Como consecuencia de tales transformaciones, los aprendientes se ven obligados a reestructurar el ciclo de vida por 
medio de una preparación o formación permanente, continua y flexible. Cuando esto ocurre, muchos miembros de la sociedad se refugian en las aulas para estudiar, actualizarse y readaptarse, en fin, seguir aprendiendo a lo largo de la vida de manera simultánea o alterna con sus trabajos, pues encuentran en ella el lugar idóneo donde encontrarán los conocimientos útiles y aplicables en el trabajo y en la vida social, lo que les ayudará a vivir mejor.

En la actualidad estamos experimentado este último cambio y debemos estar preparados para enfrentarnos, como individuos y miembros de una sociedad, de la mejor manera posible.

A modo de conclusión, afirmamos que la educación a distancia es una modalidad educativa que, a través de la historia, ha demostrado ser un complemento idóneo para la educación tradicional presencial, ya que ha abierto espacios novedosos, flexibles y de fácil acceso que han ayudado a lograr un mayor nivel de democratización de la educación superior, permitiendo con ello, que miles de personas alrededor del mundo alcancen su realización personal sin dejar de atender las responsabilidades que les exige la vida familiar, social y laboral mientras se preparan y educan.

Asimismo, la EAD además de contribuir al desarrollo social y económico, es uno de los campos educativos de mayor expansión. Su aceptación ha ganado terreno, principalmente en los países en desarrollo, debido al interés de utilizar las nuevas tecnologías en beneficio de la educación y el cumplimiento del derecho a la educación.

Los gobiernos, los empleadores privadores y las empresas deben ser los grandes inversionistas en materia de educación a distancia, pues se sabe que los resultados son pagaderos de cualquier costo, ya que a través de ella se logra: aumentar el acceso a las oportunidades educativas; ofrecer mejores oportunidades para el enriquecimiento personal y 
profesional; mejorar la relación costo-beneficio de los recursos educativos; apoyar la calidad y variedad de las estructuras educativas ya existentes, desarrollar y consolidar las capacidades; ofrecer la posibilidad de combinar la educación con el trabajo y la vida familiar; desarrollar competencias por medio de la educación continua y permanente, etc. (UNESCO, 2002)

La educación a distancia ha llegado para quedarse, tanto por su tremendo potencial como por la trascendencia que ha tenido y seguirá ofreciendo a la sociedad. Debemos valorarla, protegerla y enriquecerla, para que las generaciones actuales y las que están por venir cuenten con mayores y variadas oportunidades de educación continua, que les ayude a desempeñarse en los diversos campos de la vida y lograr su plena realización como ser humano. Hacer caso omiso a este llamado sería oponerse a su mismo bienestar, pues la educación a distancia es y seguirá siendo un recurso práctico y poderoso para la educación permanente.

\section{REFERENCIAS BIBLIOGRÁFICAS}

André, B. (s.a.) La invención de la escritura. Madrid.

Carrión, J. (s.a.). Una mirada crítica a la educación a distancia. Revista Iberoamericana de educación, 35 (8) Versión electrónica. ISSN: 1681-5653

Castellanos, C. (2004). Panorama general de los sistemas de educación a distancia. Primer congreso virtual latinoamericano de educación a distancia, del 23 de marzo al 4 de abril del 2004.

En Web: http://www.ateneonline.net/datos/ 19_01_Castellanos_Carlos.pdf

Erdos, R. (1967). "Teaching by correspondence". UNESCO.

Recuperado el 4 de noviembre de 2007 de:

http://unesdoc.unesco.org/images/0005/000539/053957eo.pdf 
Fernández, M. (2001). Educar en tiempos inciertos. Madrid: Morata.

García, L. (1987). Hacia una definición de Educación a Distancia. Boletín informativo de Ia Asociación Iberoamericana de Educación Superior a distancia. Abril. Año 4, N 18 , $4 \mathrm{pp}$.

García, L. (1999). Historia de la educación a distancia. Revista Iberoamerica de educación a distancia , 2 (1), 8-27.

García, L. (2003). La educación a distancia. Una visión global. Publicado en el Boletín Ilustre del Colegio de Doctores y Licenciados de España. N ${ }^{\circ} 146$, p. 13.

27, ISSN: $1135-4267 \mathrm{bb}$.

Garrison, D. (1985). «Three generations of technological innovation in distance education». Distance Education. №16, pp. 235-241.

Garrison, D. (1989). Understanding distance education. Londres: Routledge.

Gates, B. (10 de febrero de 2007). Educación en el siglo XXI. La Nación , pág. 28A.

Hidalgo, E. C. (2006). Una nueva visión en la educación superior: treinta años de la universidad estatal a distancia, Costa Rica. Revista iberoamericana de educación a distancia , 9 (1 y 2), 165-183.

Hidalgo, E. C. (2006). Una nueva visión en la educación superior: treinta años de la universidad estatal a distancia, Costa Rica. Revista iberoamericana de educación a distancia , 9 (1 y 2), 165-183.

Pérez, H. (s.a.). Ensayos sobre educación.

Tintaya, E. "Desafíos y fundamentos de la educación virtual". Recuperado el 4 de noviembre de 2007 de: http://www.monografias.com/trabajos13/educvirt/ educvirt.shtml

UNESCO. (2002). Aprendizaje abierto y a distancia. Consideraciones sobre tendencias, políticas y estrategias. Recuperado el 10 de febrero de 2007, de: http://unesdoc.unesco.org/ images/0012/001284/128463s.pdf 
Universidad Estatal a Distancia. Página de la UNED. Recuperado el 30 de octubre de 2007 de: http://www.uned.ac.cr/ Vásquez, E. (2005). Principios y técnicas de educación de adultos. San José: UNED. 